\title{
Perspective
}

PERSPECTIVE Actualité en histoire de l'art

Comptes rendus | 2011

Noah Hysler-Rubin, Patrick Geddes and Town

Planning: A Critical View, Londres/New York, Routledge, 2011

\section{Zeynep Çelik}

\section{(2) OpenEdition}

\section{Journals}

Édition électronique

URL : http://journals.openedition.org/perspective/2642

DOI : $10.4000 /$ perspective. 2642

ISSN : 2269-7721

Éditeur

Institut national d'histoire de l'art

Référence électronique

Zeynep Çelik, « Noah Hysler-Rubin, Patrick Geddes and Town Planning: A Critical View, Londres/New York, Routledge, 2011 », Perspective [En ligne], Comptes rendus, mis en ligne le 01 août 2013, consulté

le 01 octobre 2020. URL : http://journals.openedition.org/perspective/2642 ; DOI : https://doi.org/

10.4000/perspective.2642

Ce document a été généré automatiquement le 1 octobre 2020. 
Noah Hysler-Rubin, Patrick Geddes and Town Planning: A Critical View, Londres/New York, Routledge, 2011

Zeynep Çelik

\section{RÉFÉRENCE}

Noah Hysler-Rubin, Patrick Geddes and Town Planning: A Critical View, Londres/New York, Routledge, 2011. 
1 Hysler-Rubin propose une rééavaluation du travail urbanistique de Patrick Geddes. Puisant dans la théorie postcoloniale, elle redéfinit Geddes, considéré comme l'un des fondateurs du mouvement urbanistique moderne, comme un urbaniste colonial, et le replace ainsi dans l'histoire et la théorie urbaine. Elle analyse son idéologie à la lumière de trois lieux où il a travaillé (Grande-Bretagne, Inde et Palestine) et présente les spécificités de chaque cas d'étude. Cette perspective comparatiste lui permet de revenir sur des problèmes d'interprétation posés par des études antérieures concernant les théories et l'orientation politique de Geddes, études
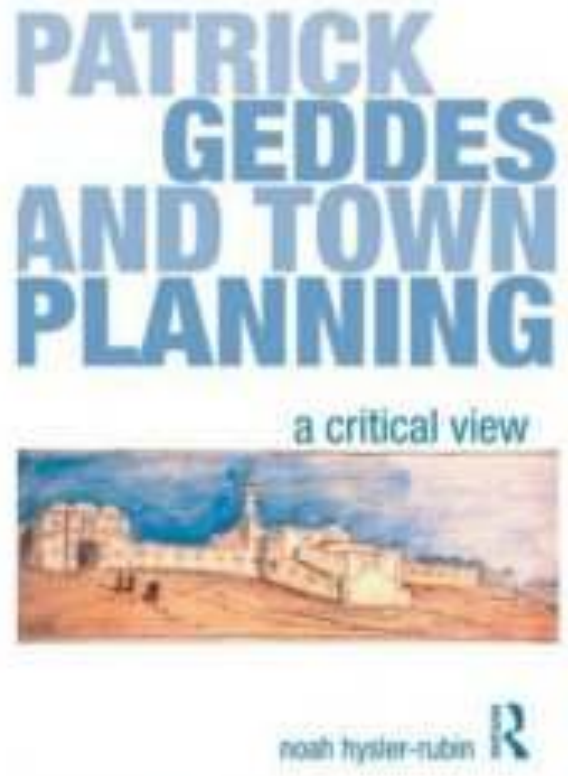
qui, selon Hysler-Rubin, ont simplifié à l'excès son discours complexe. HyslerRubin ouvre de nouvelles perspectives sur ce qu'elle appelle le caractère « inégal » et « ambivalent » du travail de Geddes. Par une argumentation soigneusement construite, elle établit les phases successives qui marquent la réception du travail de l'architecte et examine le contexte historique qui accompagne chacune de ces vagues. 